\title{
IO in late adolescence/early adulthood, risk factors in middle age and later all-cause mortality in men: the Vietnam Experience Study
}

\author{
G D Batty, ${ }^{1,2}$ M J Shipley, ${ }^{3}$ L H Mortensen, ${ }^{4,5}$ S H Boyle, ${ }^{5}$ J Barefoot, ${ }^{5}$ M Grønbæk, ${ }^{4}$ \\ C R Gale, ${ }^{6}$ I J Deary ${ }^{2}$
}

${ }^{1}$ MRC Social and Public Health Sciences Unit, University of Glasgow, Glasgow, UK; ${ }^{2}$ Department of Psychology, University of Edinburgh, Edinburgh, UK; ${ }^{3}$ Department of Epidemiology and Public Health, University College London, London, UK; ${ }^{4}$ National Institute of Public Health, University of Southern Denmark,

Copenhagen, Denmark;

${ }^{5}$ Department of Psychiatry and Behavioral Sciences, Duke University Medical Center, Durham, USA; ${ }^{6}$ MRC Epidemiology Resource Centre, University of Southampton, Southampton, UK

Correspondence to: Dr G D Batty, MRC Social \& Public Health Sciences Unit, University of Glasgow, 4 Lilybank Gardens, Glasgow G12 8RZ, UK; david-b@sphsu.mrc.ac.uk

Accepted 13 August 2007

\section{ABSTRACT}

Objective: To examine the role of potential mediating factors in explaining the 10 -mortality relation.

Design, setting and participants: A total of 4316 male former Vietnam-era US army personnel with IO test results at entry into the service in late adolescence/early adulthood in the 1960/1970s (mean age at entry 20.4 years) participated in a telephone survey and medical examination in middle age (mean age 38.3 years) in 1985-6. They were then followed up for mortality experience for 15 years.

Main results: In age-adjusted analyses, higher I0 scores were associated with reduced rates of total mortality (hazard ratio $(\mathrm{HR})_{\text {per SD increase in } 10} 0.71 ; 95 \% \mathrm{Cl} 0.63$ to 0.81). This relation did not appear to be heavily confounded by early socioeconomic position or ethnicity. The impact of adjusting for some potentially mediating risk indices measured in middle age on the IQ-mortality relation (marital status, alcohol consumption, systolic and diastolic blood pressure, pulse rate, blood glucose, body mass index, psychiatric and somatic illness at medical examination) was negligible ( $<10 \%$ attenuation in risk). Controlling for others (cigarette smoking, lung function) had a modest impact (10-17\%). Education (0.79; 0.69 to $0.92)$, occupational prestige $(0.77 ; 0.68$ to 0.88$)$ and income $(0.86 ; 0.75$ to 0.98$)$ yielded the greatest attenuation in the 10-mortality gradient (21-52\%); after their collective adjustment, the I0-mortality link was effectively eliminated (0.92; 0.79 to 1.07$)$.

Conclusions: In this cohort, socioeconomic position in middle age might lie on the pathway linking earlier 10 with later mortality risk but might also partly act as a surrogate for cognitive ability.

Higher mental ability (denoted here as IO) in childhood and early adulthood is inversely associated with all-cause mortality rates in populations followed for up to six decades. ${ }^{1}$ That is, high IO test scores seem to confer protection against premature death. Importantly, the fact that $\mathrm{IO}$ is measured in the first two decades of life in these studies, and is therefore likely to be pre-morbid, suggests that the IQ-mortality gradient is unlikely to be explained by reverse causality whereby comorbidity, rather than low cognitive function, is generating the relation.

Despite several reports of this IQ-mortality association appearing in the past five years, ${ }^{1}$ important questions remain. In particular, given that the IQ-mortality association does not seem to be explained by selection bias, statistical chance or confounding by early life factors, ${ }^{1}$ particularly socioeconomic position, there has been debate regarding the mechanisms that might underpin this gradient. ${ }^{3}$ One of the most persuasive is that the IQ-mortality gradient is mediated by established behavioural, biological, socioeconomic and psychological risk factors for premature mortality. A strong prima facie for this explanation can be found in a series of studies of populations followed into middle age showing that higher earlier IO test scores are associated with a lower prevalence of obesity, ${ }^{4-7}$ hypertension/raised blood pressure, ${ }^{7-9}$ reduced pulmonary function, ${ }^{10}$ physical inactivity, ${ }^{11}$ poor diet, ${ }^{11}{ }^{12}$ psychiatric morbidity, ${ }^{13-15}$ cigarette smoking, ${ }^{7}{ }^{916}$ socioeconomic deprivation ${ }^{17}{ }^{18}$ and heavy alcohol consumption $^{19}$ (although a positive IQ-alcohol consumption/problems relation has been reported elsewhere $\left.{ }^{20}{ }^{21}\right)$. Using an operational definition of intelligence as the ability to learn, reason and solve problems, ${ }^{18}$ one explanation advanced for a link between mental ability and later health behaviours (and therefore their physiological correlates) is the differing interpretation of sometimes complex health promotion messages pertaining to diet, exercise, alcohol consumption and smoking by individuals with differing mental ability test scores. ${ }^{16}$

Despite the growing number of studies relating IO with later risk factors for premature mortality, there is a marked paucity of cohort studies that have the capacity to examine directly the mediating impact, if any, of these risk indices in the IOmortality gradient by offering data on pre-morbid $\mathrm{IQ}$, the risk indices themselves and subsequent mortality experience. To our knowledge, only the role of the study participant's own socioeconomic position as a mediating variable in the IQ-death relation has been examined in any detail and the five studies that have explored this issue have reached differing conclusions about its role. ${ }^{22-26}$ In the only study to have examined the influence of controlling for factors other than socioeconomic position, there was no evidence that cigarette smoking mediated the relation between childhood $\mathrm{IQ}$ and total mortality. ${ }^{24}$ Other than socioeconomic position and smoking, we are unaware of any studies examining the mediating role, if any, of other risk factors for premature mortality, particularly important behavioural (heavy alcohol consumption, physical inactivity), physiological (obesity, raised blood pressure, high blood cholesterol) and psychological (depression, psychosocial stress) indices. 
The Vietnam Experience Study (VES) is a large cohort of former US army personnel that was established to compare the health profile of men who participated in the Vietnam war against those who did not. With IO assessed at entry to the army in late adolescence/early adulthood, risk factors ascertained in middle age and mortality surveillance until the year 2000, this cohort afforded us the opportunity of examining the mediating role of risk factors in the IQ-mortality link. The range of physiological, behavioural, psychological and socioeconomic risk indices collected in middle age in the VES, in addition to data on IO and mortality experience, is unprecedented.

\section{DESIGN AND METHODS \\ Background}

Following concerns that the health of Vietnam veterans may have been detrimentally affected by their military experiences, the US congress directed that a series of epidemiological studies be conducted to examine the issue. One such investigation was the VES, which took as its subjects male former Vietnam-era US army personnel who entered the service in the 1960s and 1970 s. $^{27}$ In the 1980s, study participants were identified and invited to participate in a telephone interview (1985) and a medical examination (1986). ${ }^{28-30}$

\section{Study participants}

Study participants were identified retrospectively using existing military records, a process that has been described in detail elsewhere. ${ }^{27}{ }^{31}$ In brief, as illustrated in fig 1, subjects were drawn from approximately five million US Vietnam-era army service files stored at the National Personnel Records Center. Five inclusion criteria were applied: entered military service between 1 January 1965 and 31 December 1971; served only one term of enlistment; served at least 16 weeks of active duty; earned a military specialty other than "trainee" or "duty soldier" and at discharge from active duty had a military pay grade no higher than sergeant. On reviewing a random sample of 48513 records, 1355 were found to be incomplete, 28577 did not meet study entry criteria and 268 men died during military duties. The remainder, 18313 former military personnel, qualified for inclusion in the study cohort.

\section{Data collection in late adolescence/early adulthood}

Information pertaining to place of service, military rank, ethnicity and IO were extracted from military archives. Participants were designated as being Vietnam veterans if they had served at least one tour of duty in Vietnam and as nonVietnam veterans if they did not (this group included men who served one or more tours of duty in Korea, Germany or the United States). Based on military rank at discharge from the army (mean age 22.5 years, range 17.9-36.8), the monthly income of the army personnel based on 1964 pay scales was derived: US\$83; US\$86; US\$99; US\$120 and US\$145 (highest income with rank comparable to sergeant). The ethnic origin of the study members was classified as "white", "black", or "other"; the latter group comprising Hispanic and Asian individuals, Pacific Islanders, American Indians and Alaskan natives.

On enlistment into military service, study participants were routinely administered a general aptitude test: the Army General Technical Test (hereafter referred to as "IO"). This consists of two subtests, verbal and arithmetic reasoning. We were able to validate this test by comparing scores from it with those from components of the Wechsler Adult Intelligence Scale, a comprehensive and widely used test of cognitive ability that was administered to study participants $(\mathrm{N}=4411)$ during the medical examination during middle age (described below). Despite this intervening period, total Army General Technical Test results were strongly correlated with information subtest scores ( $r=0.75 ; 95 \%$ confidence intervals (CI) 0.73 to 0.76 ) and block design scores $(0.51 ; 0.49$ to 0.51$)$ from the Wechsler Adult Intelligence Scale. Mean age at army entry when IO was assessed was 20.4 years (range 17.0-33.8).

\section{Data collection in middle age: telephone survey}

The vital status of men between army discharge and 31 December 1983 (the date the cohort was established) was ascertained by cross-checking against a variety of mortality databases supplied by the US army, the Veterans Administration (Beneficiary Identification and Records Locator Subsystem), the Social Security Administration, the Internal Revenue Service and the National Center for Health Statistics (National Death Index). All potential matches were manually reviewed. Of 18313 former military personnel who qualified for inclusion in the original study cohort, 446 were found to have died post-discharge (fig 1). The remainder $(\mathrm{N}=17$ 867) were considered to be alive on 31 December 1983 and therefore eligible for active follow-up through means of interview and medical examination. Telephone directories, credit bureau searches, driver's licence and motor vehicle registration records, city directories, local records and personal field visits were all utilised to locate the whereabouts of apparently surviving men. In all, 1488 could not be traced. Of those traced ( $N=16349)$, an interview was not possible for reasons of incarceration ( $\mathrm{N}=63$ ), physical or mental disability (20), refusal (949), death during the tracing process (53), or 'other' (six). This resulted in 15288 men (85.6\% of those alive on 31 December 1983) participating in the 1985 telephone survey.

During the telephone survey, enquiries were made about the study participants' health, health behaviours and socioeconomic characteristics. In brief, socioeconomic position was measured using years of completed education, household income and an index of occupational prestige. ${ }^{32} 33$ Smoking habits and marital status were ascertained using standard questions. Enquiries were also made as to the presence of a range of physiciandiagnosed health problems, which included hypertension, cancer, diabetes and coronary heart disease. ${ }^{28} 29$

\section{Data collection in middle age: medical examination}

In 1986, a random sample of telephone interview respondents $(\mathrm{N}=6443)$ was invited to attend a three-day medical examination with orientation at a single facility in Albuquerque, New Mexico, USA, for which travel expenses and a nominal stipend were provided; 4462 attended. This represented $69 \%$ of the random sample invited to the medical examination (25\% of all cohort survivors); approximately one third $(\mathrm{N}=1645)$ were originally military service volunteers. Mean age at medical examination was 38.3 years (range $31.1-$ 49.0).

All men were requested to fast from 19:00 hours the evening before medical testing. After the drawing of blood the following morning, levels of triglycerides and cholesterol fractions were ascertained using a Kodak Ektachem 700 autoanalyser. ${ }^{29}$ Serum glucose level was determined using a standard adaptation of the glucose oxidase-peroxidase-chromogen-coupled system for glucose determination in biological fluids. ${ }^{29}$ 
Figure 1 Sampling in the Vietnam Experience Study.

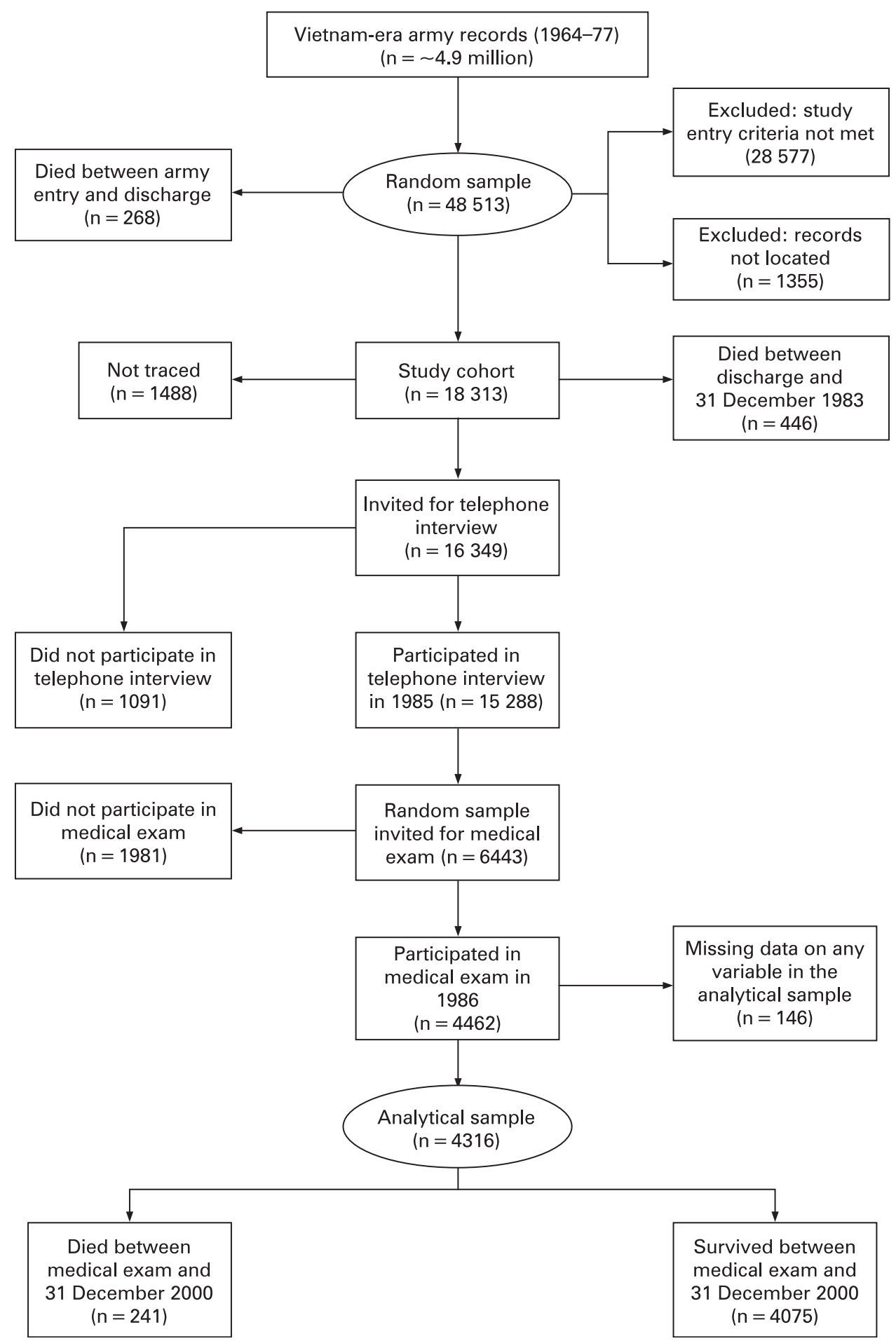

With the participant in a sitting position, blood pressure was measured twice in the right arm using a standard mercury sphygmomanometer; for the purposes of analyses, an average was computed. Resting heart rate, an indicator of cardiorespiratory fitness and therefore a proxy for regular physical activity, ${ }^{34}{ }^{35}$ was also recorded. Lung function, as indexed by forced expiratory volume in one second $\left(\mathrm{FEV}_{1}\right)$, was determined using spirometry. Height and weight, measured using standard protocols, were used to calculate body mass index $\left(\mathrm{kg} / \mathrm{m}^{2}\right)$. Regarded as an adult marker of childhood exposures that might include nutrition, psychosocial stress and social circumstances, ${ }^{36}$ height was also included as a risk factor in its own right given its inverse association with total mortality across several studies. ${ }^{37}$ Although measured in adulthood, we therefore theorised stature as a confounding variable in the IQ-mortality relation..$^{38}$

Psychological health was assessed using the Diagnostic Interview Schedule (version $3 \mathrm{~A})^{39}$ as administered by a trained psychological technician. The Diagnostic Interview Schedule is a standardised questionnaire that is designed to assess the prevalence of certain psychiatric conditions according to the Diagnostic and Statistical Manual of Mental Disorders (version III) criteria of the American Psychiatric Association. ${ }^{39-41}$ Study 
Table 1 Comparison of selected characteristics of men in the Vietnam Experience Study included in the analytical sample with those excluded

\begin{tabular}{|c|c|c|c|}
\hline \multirow{2}{*}{\multicolumn{2}{|c|}{ Characteristic }} & \multirow{2}{*}{$\begin{array}{l}\text { Included } \\
(N=4316)\end{array}$} & \multirow{2}{*}{$\begin{array}{l}\text { Excluded } \\
(N=13997)^{*}\end{array}$} \\
\hline & & & \\
\hline \multicolumn{2}{|l|}{ IO at army entry, mean, SD } & $106.1(20.1)$ & $103.8(20.4)$ \\
\hline \multicolumn{2}{|c|}{ Age at telephone interview $\dagger$, years $(\%(N)) \leqslant 34$} & $12.2(527)$ & $13.0(1818)$ \\
\hline & $35-39$ & $68.0(2935)$ & $67.5(9451)$ \\
\hline & $\geqslant 40$ & $19.8(854)$ & $19.5(2728)$ \\
\hline \multirow[t]{3}{*}{ Army income, US\$/month (\% (N)) } & 145 & $38.0(1640)$ & $35.0(4896)$ \\
\hline & $120-144$ & $49.5(2135)$ & $48.2(6751)$ \\
\hline & $83-119$ & $12.5(541)$ & $16.8(2350)$ \\
\hline \multirow[t]{3}{*}{ Place of service $(\%(\mathrm{~N}))$} & Served in USA only & $19.0(818)$ & $21.8(3051)$ \\
\hline & Other overseas posting & $25.7(1110)$ & $28.7(4010)$ \\
\hline & Ever served in Vietnam & $55.3(2388)$ & $49.6(6936)$ \\
\hline \multirow[t]{3}{*}{ Ethnic group (\% (N)) } & White & $81.8(3529)$ & $83.0(9104)$ \\
\hline & Black & $11.8(510)$ & $10.8(1184)$ \\
\hline & Other & $6.4(277)$ & $6.2(684)$ \\
\hline \multicolumn{2}{|l|}{ Hazard ratio: $(95 \% \mathrm{CI})$} & 0.71 (0.63 to 0.81$)$ & $0.78(0.73$ to 0.84$)$ \\
\hline
\end{tabular}

\footnotetext{
${ }^{*}$ Numbers vary slightly as a result of missing data.

$\dagger$ For those in the excluded group who did not complete a telephone interview, age is taken at the midpoint date (31 July 1985) of the telephone interviews.

H.Hazard ratios are for a 1 SD increase in 10 in relation to all-cause mortality and are adjusted for age. In these analyses, mortality follow-up is from the date of telephone interview or the midpoint date (31 July 1985) for those who did not participate in the telephone interview; the 499 subjects who died before 31 July 1985 are excluded from this analysis.

With the exception of age at telephone interview, all data were extracted from military records.
}

participants were considered positive for depression, generalised anxiety disorder and posttraumatic stress disorder if they reported a pattern of symptoms in the previous year that satisfied full Diagnostic and Statistical Manual of Mental Disorders (version III) criteria. The veterans also reported their frequency of alcohol bingeing (defined as five or more "drinks" on one occasion; a bottle/can beer, glass of wine, a cocktail, or measure of spirits constituted a drink).

\section{Statistical analysis}

For continuous covariates, least squares means were used to present the age-adjusted means across IO quintiles and a linear trend term was fitted to test for an overall association. For dichotomous covariates, trends in proportions across IO quintiles were tested for significance by using the MantelHaenszel test adjusted for age in three groups. The association between IO quintiles and categorical covariates with more than two levels were tested using a chi-square test for heterogeneity adjusted for age in three groups. Hazard ratios (HR) and accompanying 95\% CI were computed for the relation of individual covariates and IQ with total mortality using a Cox's proportional hazards regression model with follow-up time as the underlying time scale. ${ }^{42}$ The proportional hazards assumption for IO was tested by fitting interaction terms between IO and the logarithm of follow-up time and was found not to be violated. In these analyses, IQ was utilised as a continuous measure (HR computed per $1 \mathrm{SD}$ increase) and, in order to examine dose-response effects, a categorical variable (HR computed across quintiles). Follow-up time was taken from the date of the telephone survey until censoring, death or 31 December 2000, which ever came first (mean follow-up time 15.1 years). All analyses were performed with the use of SAS software, version 8.2 (SAS Institute, Cary, North Carolina, USA).

In these analyses we adjusted separately for variables that we conceptualised as potential confounding factors (age at telephone survey, country of posting, army income, ethnicity and height) and those that we regarded as potential mediating factors (marital status, smoking habit, alcohol consumption, occupational prestige, educational grade, income, lung function, total cholesterol and fractions, systolic blood pressure, diastolic blood pressure, pulse rate, blood glucose, body mass index, posttraumatic stress disorder, depression, generalised anxiety disorder and somatic illness). Given the debates over the utilisation of education, a close correlate of $\mathrm{IO}$, as a mediating variable, ${ }^{1}$ we produced fully adjusted models with and without entering this variable. Only those covariates that revealed themselves to be related to both IQ and all-cause mortality were used in analyses examining the impact of their adjustment on the IQ-death gradient. To estimate the impact of controlling for a given covariate we utilised the following formulae as we have elsewhere ${ }^{43}$ :

$$
\begin{gathered}
\left(\left[\mathrm{HR}_{\text {age-adjusted }}-1\right]-\left[\mathrm{HR}_{\text {risk factor-adjusted }}-1\right] /\left[\mathrm{HR}_{\text {age-adjusted }}-\right.\right. \\
1]) \times 100
\end{gathered}
$$

The present analyses are largely based on a sample of men with complete information on IQ, covariates at telephone interview and medical examination and mortality $(\mathrm{N}=4316)$. This group represents $67 \%$ of the random subsample invited to the medical examination and $26 \%$ of individuals originally enrolled in the study. Although the latter is based on a random sample of surviving men, concerns are nonetheless raised about selection bias; that is, if the reported results differ markedly between individuals included in the analyses and those not included. To examine this issue we compared the distribution of selected characteristics between these two groups (table 1). Men in the excluded group had a marginally lower IO score than those in the analytical sample; however, there was generally little evidence of any systematic differences between the groups. This was confirmed when we computed the relation between $\mathrm{IO}$ and all-cause mortality in each of the groups for individuals with available data. The strength of this association $\left(\mathrm{HR}_{\text {per } 1 \mathrm{SD}}\right.$ increase in IO; $95 \% \mathrm{CI}$ ) was similar in men included $(0.71 ; 0.63$ to $0.81)$ and excluded (0.79; 0.75 to 0.84$)$ from the analyses ( $p$ value for difference 0.22 ). 
Table 2 IQ in relation to study participant characteristics in the Vietnam Experience Study $(N=4316)$

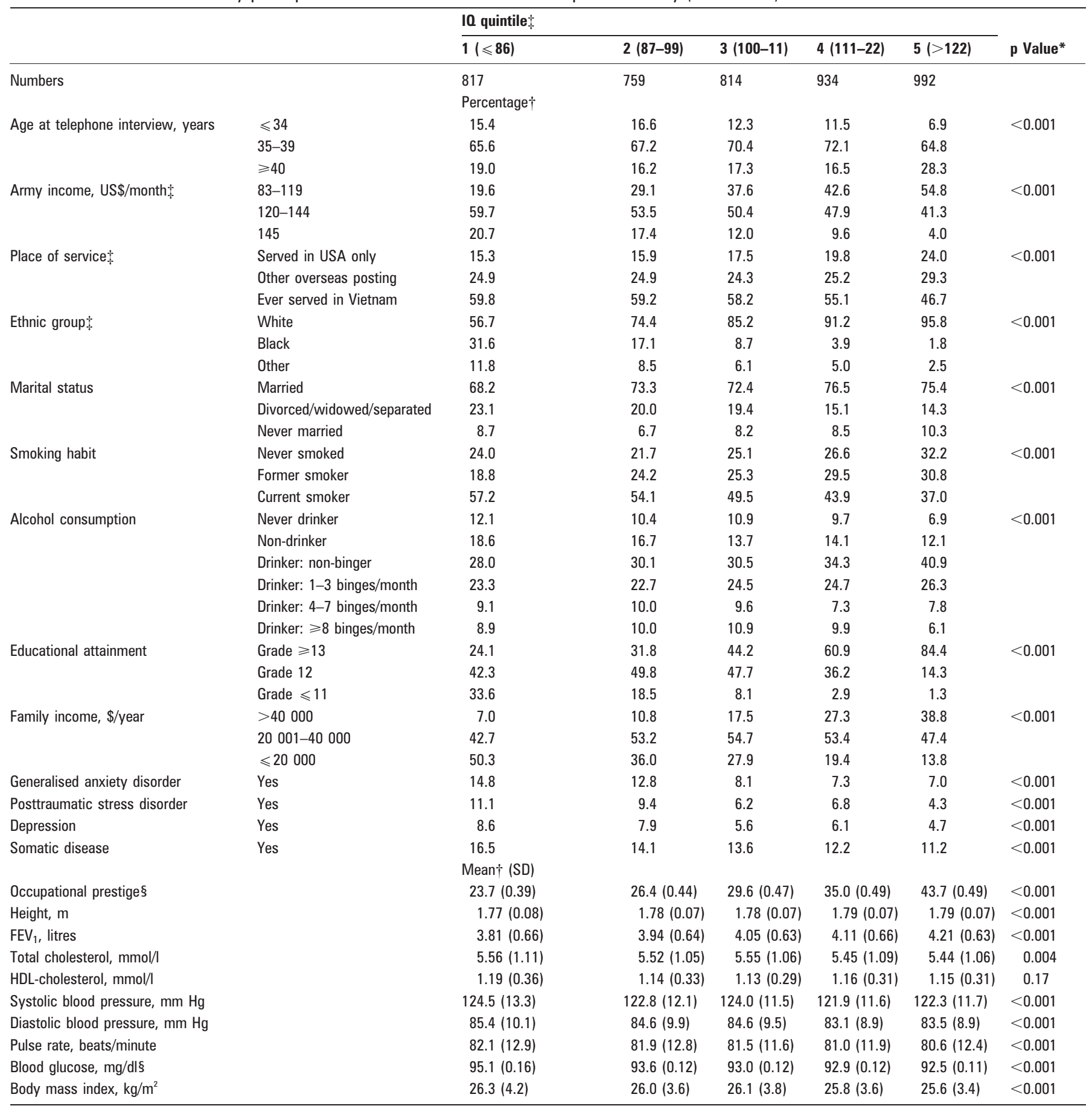

$\mathrm{FEV}_{1}$, Forced expiratory volume in one second; HDL, high-density lipoprotein.

All data were collected during telephone survey and medical examination unless otherwise indicated.

* $p$ Value for trend for dichotomous and continuous measures; otherwise, $p$ value for heterogeneity.

$\dagger$ All means and percentages (apart from age) are adjusted for age.

DData extracted from military records.

$\S$ Geometric mean with SE of logged variable in brackets.

\section{RESULTS}

In table 2 the relations between IO and study covariates are presented. IO was associated with indicators of socioeconomic position during military service (army income) and in middle age (education, income and occupational prestige), such that there was a lower level of disadvantage in the higher IO scoring groups. Higher IO scores in early adulthood were apparent in veterans who were somewhat older at telephone survey, white, those whose place of service did not include Vietnam and those who were married. Men with higher IO scores at entry to the army were less likely subsequently to smoke, binge drink and report a series of psychological and somatic health conditions, including posttraumatic stress disorder, depression, generalised anxiety disorder and conditions that comprised somatic illness (coronary heart disease, hypertension, cancer and diabetes). Higher IQ scoring men also had lower total cholesterol, systolic and diastolic blood pressure, pulse rate, fasting blood glucose, pulmonary function and body mass index. Not all of the 
Table 3 Hazard ratio $(95 \% \mathrm{Cl})$ for the relation of covariates with total mortality in the Vietnam Experience Study $(\mathrm{N}=4316)$

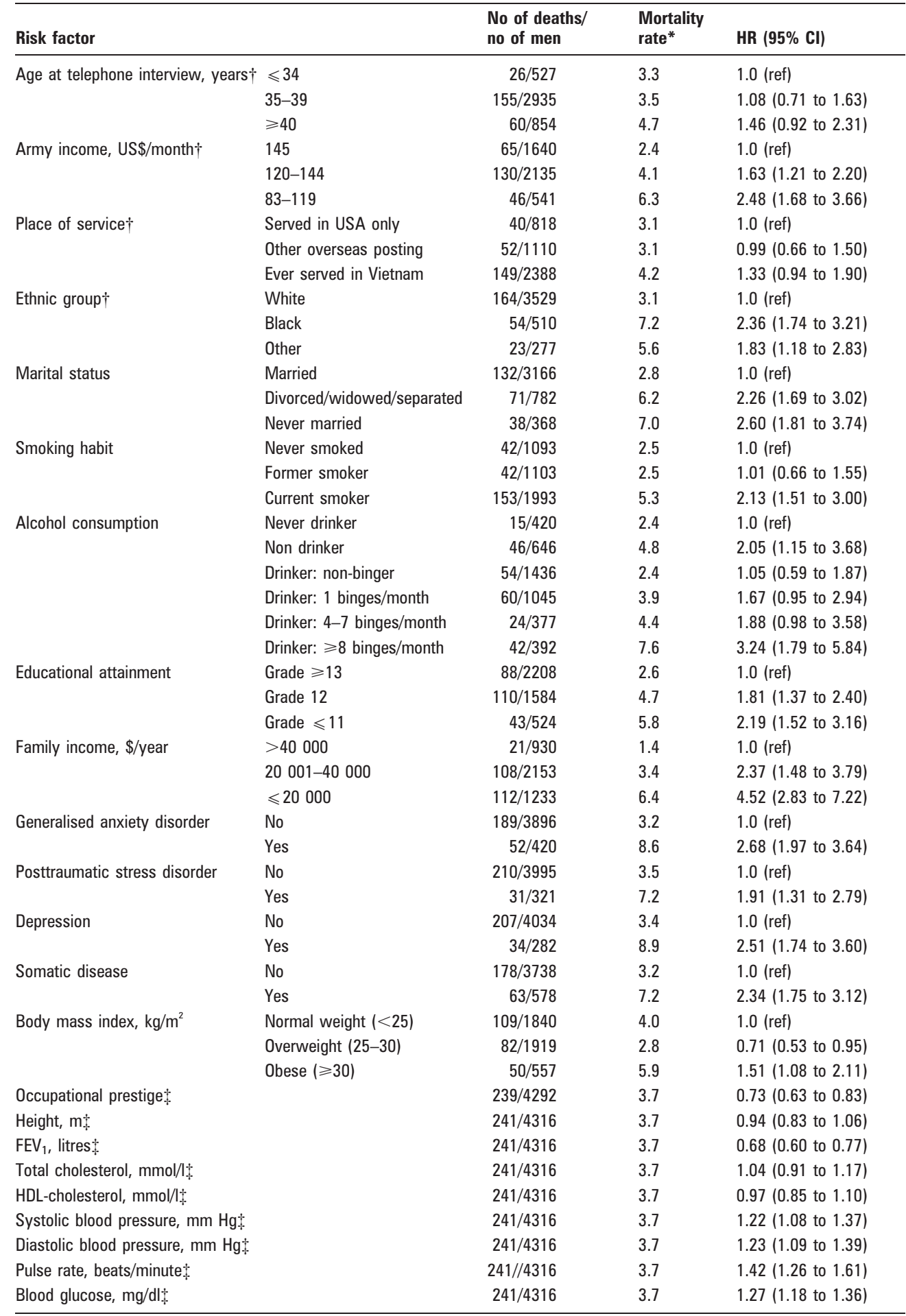

$\mathrm{FEV}_{1}$, Forced expiratory volume in one second; HDL, high-density lipoprotein; HR, hazard ratio.

All data collected during telephone survey and medical examination unless otherwise indicated.

*Units are per 1000 person-years.

†Data extracted from military records.

HHR shown are for a 1 SD increase in risk factors and are age-adjusted (apart from age).

aforementioned associations were, however, incremental across the IO groups.

Table 3 shows the age-adjusted relation of each study covariate with mortality risk. Fifteen years of follow-up gave rise to 241 deaths from all causes (comprising 63 deaths from cardiovascular disease, 48 cancers, 28 accidents, 18 digestive causes, 13 suicides, 5 respiratory and 66 from "other" causes). Socioeconomic disadvantage, as indexed by any one of four markers, was associated with elevated mortality rates. Not marrying or losing a partner through divorce, separation or widowhood was also associated with greater death rates. Smoking and heavy drinking men also experienced an elevated 


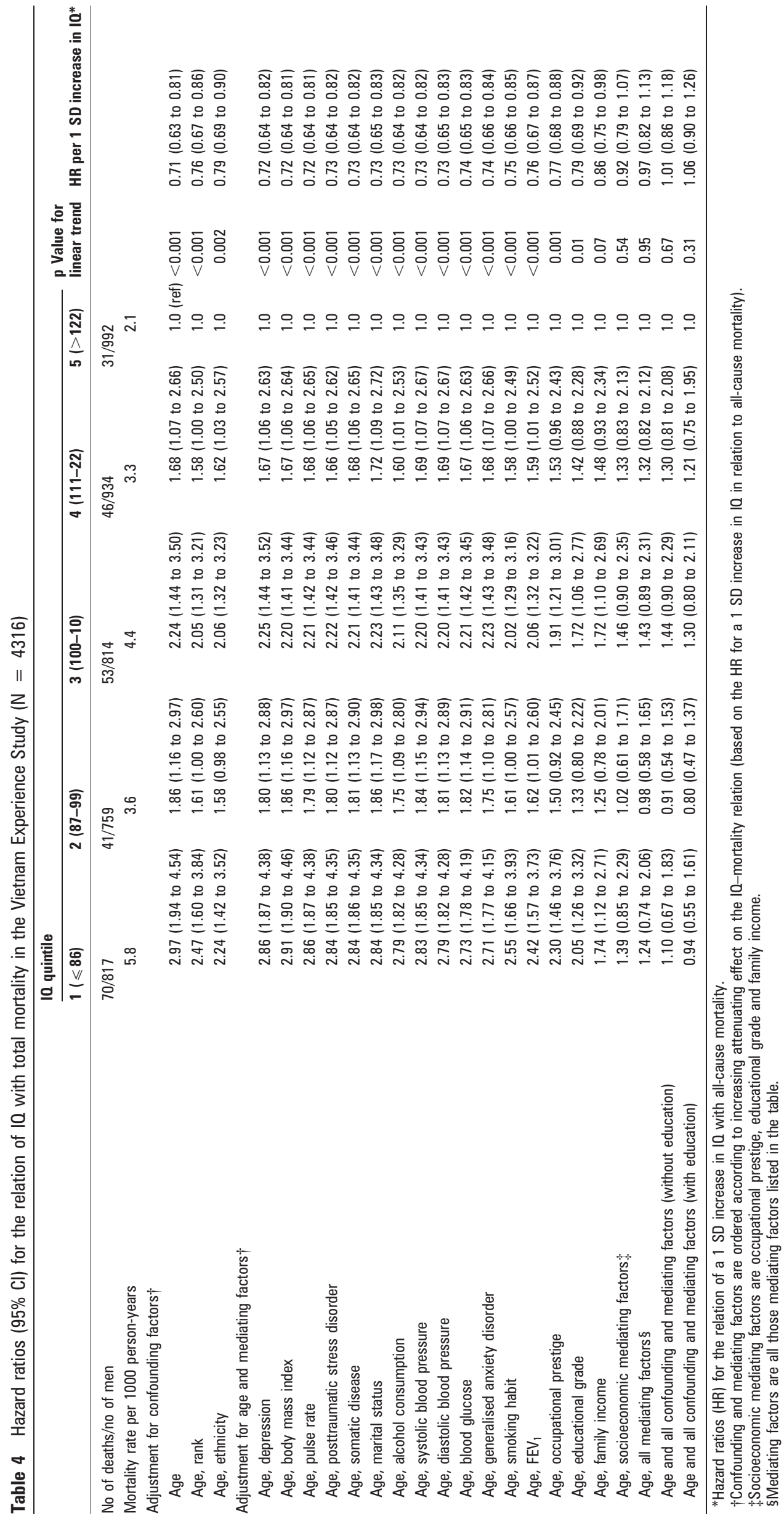


mortality risk, as did those with higher systolic and diastolic blood pressure, body mass index (obesity but not overweight), fasting glucose and resting pulse rate. Men who reported experiencing symptoms of depression, anxiety, posttraumatic stress disorder and somatic illness were at greater risk of death than their disease-free counterparts. Pulmonary function as measured by $\mathrm{FEV}_{1}$ was inversely associated with mortality risk.

In table 4 we depict the relation between IO and later mortality risk adjusted individually and collectively for a range of potential confounding and mediating variables. As indicated, in our multivariable models we only include those factors that were associated with both IO and all-cause mortality. In ageadjusted analyses there was an inverse association between IO and mortality risk, such that the higher test scores were associated with reduced mortality rates $\left(\mathrm{HR}_{\text {per }} 1 \mathrm{SD}\right.$ increase in $\mathrm{IQ}$ $0.71 ; 95 \%$ CI 0.63 to 0.81 ). There was some evidence of a graded increase in risk across the lower IQ quintiles ( $p$ value for trend $<0.001$ ), although this was not completely stepwise, with some flattening of risk in the central IO groups. Adjustment for the individual confounding variables of army income and place of service had little impact on this relation, whereas control for ethnicity attenuated the IQ effect by $28 \%(0.79 ; 0.69$ to 0.90$)$.

Next, we adjusted for a range of physiological, behavioural, psychological and social risk factors that can be considered as mediating variables in the IQ-mortality relation. The influence of controlling for these factors can be broadly divided into three strata. In the first, despite being associated with both IO and mortality, adjusting individually for marital status, alcohol consumption, systolic and diastolic blood pressure, pulse rate, blood glucose, body mass index and psychiatric and somatic illness at medical examination had very little, if any, impact on the age-adjusted $\mathrm{IQ}$-death relation ( $<10 \%$ attenuation in risk). In a second strata of impact, controlling for smoking $(0.75 ; 0.66$ to 0.85 ) and lung function (0.76; 0.67 to 0.87 ) marginally reduced the strength of the IO-mortality link (10-17\% attenuation in risk). Markers of socioeconomic circumstances in middle age had the strongest attenuating effects on the association between IQ and mortality. In a third strata (21$52 \%$ ), adjustment for occupational prestige weakened the IQmortality association by $21 \%(0.77 ; 0.68$ to 0.88$)$, education by $28 \%(0.79 ; 0.69$ to 0.92$)$ and income by $52 \%(0.86 ; 0.75$ to 0.98$)$, although statistical significance at conventional levels was retained. Little evidence of the IQ-mortality link remained, however, after collective adjustment for these indices of socioeconomic position $(0.92 ; 0.79$ to 1.07$)$ and, similarly, all potential mediating factors combined $(0.97 ; 0.82$ to 1.13$)$. When the full model contained education, a close correlate of $\mathrm{IQ}$, results were essentially the same as when it was omitted.

\section{DISCUSSION}

The main objective of this report was, for the first time, to examine the role of a range of physiological, socioeconomic, psychological and behavioural risk factors for premature mortality in generating the $\mathrm{IO}$-death relation. When these aforementioned risk indices were added to the multivariable models, those yielding the greatest attenuation in risk were education, occupational prestige and income and, to a lesser extent, smoking and lung function (themselves strongly interrelated). Apart from income, which weakened the IQmortality association by $52 \%$, all other risk factors attenuated this relation by $28 \%$ or less. Adjusting for physiological factors other than lung function (eg, blood pressure, obesity, serum cholesterol) had essentially no impact on the IQ-death relation.
Mediating role of education and other markers of socioeconomic position

It may be that education, occupational prestige and income are part of a pathway linking IO with mortality, whereby high IO scores in childhood/early adulthood lead to educational success, placement into well paid employment, enhanced social status and the accompanying benefits to health that the latter has repeatedly been shown to confer. ${ }^{44}$ Alternatively, it is also plausible that educational attainment may represent at least a partial proxy for individual differences in $\mathrm{IO}^{45}{ }^{46}$ and in cognitive domains not examined in the mental ability tests taken by our participants. As such, including education in our statistical models may be seen as overadjustment: in the present cohort $(r=0.55)$ and in one with very detailed educational data $(r=0.81)^{47}$ education and mental ability are closely related. To our knowledge, ${ }^{1}$ five other studies ${ }^{22-26}$ have evaluated whether adult socioeconomic position could account for the IQmortality gradient. In three of these-the Nun Study, ${ }^{22}$ the Australian Army Veterans Study ${ }^{23}$ and the 1946 British birth cohort study ${ }^{24}$ - the indicator of social circumstances was education. The pattern of effects after adjustment for the different markers of education is not consistent across studies, with both a strengthening ${ }^{22}$ and attenuation ${ }^{23}{ }^{24}$ of the IOmortality relation reported.

The period of IO measurement in the present study would not have preceded educational attainment for the majority of the cohort who would generally not have gone on to higher education. This notwithstanding, in studies that have explored the stability of IQ scores across the life course, there is evidence that tracking of individual differences is high. For example, in a cohort of 11-year-old Scottish children who were retested 66 years later, a strong correlation was apparent $(r=0.73) .{ }^{48}$ As such, it seems that individual differences in IQ scores in late adolescence/early adulthood in this cohort will closely recapitulate the individual differences in childhood. Therefore, although our measurement of IO did not temporally precede that of education, we nonetheless believe we have an excellent indication of earlier IO scores.

Part of the process of examining of the mediating role of the afore-described risk factors involved relating them to both IO and mortality. In doing so, many well established risk factordeath relations were supported. The link between IO and these risk factors has a shorter research tradition. In addition to adding to the few studies to have examined the relation of premorbid IQ with heavy drinking, depression, posttraumatic stress disorder and lung function, we were able to demonstrate, for the first time, an association between higher IO scores and a favourable level of generalised anxiety disorder, total cholesterol, blood glucose and cardiorespiratory fitness (as indexed by pulse rate).

\section{Shape of the I0-mortality relation and role of confounding}

In addition to facilitating an examination of the potential mechanisms underlying the IO-mortality relation, we were also able, in part, to explore two other outstanding issues in this field: the shape of the IQ-mortality curve (ie, threshold versus incremental) and the role of potential confounding variables. Four studies 25264950 have explored dose-response effects by computing mortality rates across three or more IO groups. Three 264950 found a stepwise increase in mortality risk in successively lower quartiles of $\mathrm{IO}$. In the present study there was evidence of a graded relation across the IQ range, with only slight evidence of departures from this general trend. Interpretation of this result is somewhat hampered by a 
moderate number of deaths that is lower than some other studies in this field, which themselves are limited by having few covariates.

An often cited alternative explanation for the relation between high pre-adult IO and reduced mortality is confounding. Given its relation with both $\mathrm{IQ}^{18}$ and mortality risk, ${ }^{51}$ socioeconomic position in early life is most frequently advanced as an important confounder in the IQ-mortality link. ${ }^{2}$ Only three previous studies ${ }^{24}{ }^{50}$ have evaluated the effect of early social circumstances on the IQ-mortality gradient. In two ${ }^{24} 50$ there was some evidence of attenuation of risk, albeit modest, whereas in the third ${ }^{26}$ there was no weakening of effect. In the present study we took account of differences across IQ scores according to socioeconomic position by adjusting for army income, an indicator of social status around labour market entry, and the IQ-mortality gradient was only partly confounded. It may be that army income based on rank is likely to be an imperfect index of socioeconomic position in early adulthood; it would, at least partly, have been based on the results of the $\mathrm{IO}$ tests administered on entry to service. That is, personnel with higher IO scores may have been more likely to be placed higher up the military hierarchy, as evidenced by the moderate correlation between this factor and IO $(r=0.28$, $\mathrm{p}<0.001)$. By adjusting for army income, therefore, it is probable that we have underestimated some of the effect of IQ on mortality experience. We also found that adjustment for ethnicity led to a reduction in the strength of the IQ-mortality relation, although statistical significance was retained.

\section{Study strengths and limitations}

This study has a number of strengths, not least the far greater range of potential confounding and mediating risk factors than has been previously examined in a single dataset. It is not, however, without limitations. First, this cohort solely comprises men. As far as we are aware, only two studies ${ }^{24}{ }^{49}$ have reported sex-specific analyses when examining the IO-total mortality relation. In the larger study, the SMS $1932,{ }^{49}$ a protective effect of high IO scores was seen in both men and women, whereas there was little evidence of such a gradient in women in a follow-up of the 1946 British Birth Cohort Study. ${ }^{24}$ In the women-only Nun Study, ${ }^{22}$ two non-standard indicators of cognitive ability derived from biographies at entry to the order demonstrated inverse associations with mortality. Further data are clearly required to assess any differential effect between the sexes with respect to IO and survival. Second, the range of IO scores in the present cohort may be narrower than in general population groups, not only due to the occupational nature of the population studied (the "healthy worker" effect) but also because, from the outset, personnel with a rank corresponding to above sergeant were excluded from the study sample. Even reducing the variation of the exposure, in this case IQ, by small to even modest amounts is unlikely to result in a marked underestimation of the association.

In conclusion, in the present study, the association between early adult IO and later mortality risk appeared to be completely mediated by socioeconomic disadvantage in middle age, suggesting one pathway linking cognition with mortality risk, although there are other plausible interpretations of this result, not least the possibility that adult socioeconomic position serves only as a proxy for IO, which itself has a direct effect on mortality risk. Further examination of this observation is justified, particularly in women and minority groups.

\section{What this study adds}

- This is the most comprehensive examination to date of the role of mediating factors in generating the $\mathrm{IO}$-mortality link.

- Higher I0 scores in late adolescence/early adulthood were associated with more favourable levels of a range of behavioural, physiological, psychological and socioeconomic risk factors in middle age.

- Of these risk factors, cigarette smoking, lung function and, in particular, indicators of socioeconomic position, had the strongest mediating effect on the IQ-mortality relation.

\section{Policy implications}

The skills captured by IO tests, such as verbal comprehension and reasoning, may be important in the successful management of an individual's risk factor profile and mortality experience.

Acknowledgements: The authors would like to thank the referees (Debbie Lawlor and two who remain anonymous) for their very constructive comments.

Funding: Mortality surveillance of the cohort in the post-service VES was funded by the National Center for Environmental Health in Atlanta, USA. GDB is a Wellcome Trust Fellow. MJS is supported by the British Heart Foundation, LHM and MG by the National Institute of Public Health, Denmark, and JB and SHB by the National Heart Lung and Blood Institute and the National Institutes on Aging of the US National Institutes of Health (grant no R01-HL54780). IJD is the recipient of a Royal SocietyWolfson Research Merit Award.

Competing interests: None.

Contributors: GDB and LHM generated the idea for these analyses, which was developed by IJD and MJS. LHM built the data set which was analysed by MJS. SHB and JB provided guidance on the data collected during the telephone and medical surveys. GDB wrote the first draft of this manuscript to which all authors subsequently contributed.

\section{REFERENCES}

1. Batty GD, Deary IJ, Gottfredson LS. Premorbid (early life) IO and later mortality risk: systematic review. Ann Epidemiol 2007;17:278-88.

2. Batty GD, Deary IJ. Early life intelligence and adult health. BMJ 2004;329:585-6.

3. Deary IJ, Batty GD. Commentary: pre-morbid IO and later health-the rapidly evolving field of cognitive epidemiology. Int J Epidemiol 2006;35:670-2.

4. Sorensen TI, Sonne-Holm S, Christensen U. Cognitive deficiency in obesity independent of social origin. Lancet 1983;1:1105-6.

5. Teasdale TW, Sorensen TI, Stunkard AJ. Intelligence and educational level in relation to body mass index of adult males. Hum Biol 1992;64:99-106.

6. Chandola T, Deary IJ, Blane D, et al. Childhood IO in relation to obesity and weight gain in adult life: the National Child Development (1958) Study. Int J Obes (Lond) 2006;30:1422-32.

7. Batty GD, Deary IJ, Schoon I, et al. Mental ability across childhood in relation to risk factors for premature mortality in adult life: the 1970 British Cohort Study. J Epidemiol Community Health 2007;61:997-1003.

8. Lindgarde $\mathbf{F}$, Furu $\mathrm{M}$, Ljung BO. A longitudinal study on the significance of environmental and individual factors associated with the development of essential hypertension. J Epidemiol Community Health 1987;41:220-6.

9. Batty GD, Deary IJ, Macintyre S. Childhood IO in relation to risk factors for premature mortality in middle-aged persons: the Aberdeen Children of the 1950s study. J Epidemiol Community Health 2007;61:241-7.

10. Deary IJ, Whalley LJ, Batty GD, et al. Physical fitness and lifetime cognitive change Neurology 2006;67:1195-200.

11. Batty GD, Deary IJ, Schoon I, et al. Childhood mental ability in relation to food intake and physical activity in adulthood: the 1970 British Cohort Study. Pediatrics 2007;119:e38-45.

12. Gale CR, Deary IJ, Schoon I, et al. IO in childhood and vegetarianism in adulthood: 1970 British cohort study. BMJ 2007;334:245

13. Zammit S, Allebeck P, David AS, et al. A longitudinal study of premorbid I0 score and risk of developing schizophrenia, bipolar disorder, severe depression, and other nonaffective psychoses. Arch Gen Psychiatry 2004;61:354-60.

14. Batty GD, Mortensen EL, Osler M. Childhood IQ in relation to later psychiatric disorder: evidence from a Danish birth cohort study. Br J Psychiatry 2005;187:180-1. 
15. Gunnell D, Harrison G, Rasmussen F, et al. Associations between premorbid intellectual performance, early-life exposures and early-onset schizophrenia. Cohort study. Br J Psychiatry 2002;181:298-305.

16. Taylor MD, Hart CL, Davey Smith G, et al. Childhood mental ability and smoking cessation in adulthood: prospective observational study linking the Scottish Mental Survey 1932 and the Midspan studies. J Epidemiol Community Health 2003;57:4645.

17. Deary IJ, Taylor MD, Hart C, et al. Intergenerational social mobility and mid-life status attainment: influences of childhood intelligence, childhood social factors, and education. Intelligence 2005;33:455-72.

18. Neisser U, Boodoo G, Bouchard T Jr, et al. Intelligence: knowns and unknowns. Am Psychol 1996:51:77-101.

19. Batty GD, Deary IJ, Maclntyre S. Childhood IO and life course socioeconomic position in relation to alcohol induced hangovers in adulthood: the Aberdeen children of the 1950s study. J Epidemiol Community Health 2006:60:872-4.

20. Hatch SL, Jones PB, Kuh D, et al. Childhood cognitive ability and adult mental health in the British 1946 birth cohort. Soc Sci Med 2007;64:2285-96.

21. Batty GD, Deary IJ, Schoon I, et al. Childhood mental ability in relation to alcohol drinking problems and consumption in adulthood: the 1970 British Cohort Study. Am J Public Health 2008; in press.

22. Snowdon DA, Greiner L, Kemper $S$, et al. Linguistic ability in early life and longevity: findings from the Nun Study. In: Robine J-M, Forette B, Franceschi C, Allard M, eds. The paradoxes of longevity. New York: Springer, 1999:103-13.

23. O'Toole BI, Adena MA, Jones MP. Risk factors for mortality in Australian Vietnamera national servicemen: a case-control study. Community Health Stud 1988;12: 408-17.

24. Kuh D, Richards M, Hardy $R$, et al. Childhood cognitive ability and deaths up until middle age: a post-war birth cohort study. Int J Epidemiol 2004;33:408-13.

25. Hart CL, Taylor MD, Davey Smith G, et al. Childhood I0, social class, deprivation, and their relationships with mortality and morbidity risk in later life: prospective observational study linking the Scottish Mental Survey 1932 and the Midspan studies. Psychosom Med 2003;65:877-83.

26. Hemmingsson T, Melin B, Allebeck $P$, et al. The association between cognitive ability measured at ages 18-20 and mortality during 30 years of follow-up-a prospective observational study among Swedish males born 1949-51. Int J Epidemiol 2006;35:665-70.

27. The Centers for Disease Control Vietnam Experience Study. Postservice mortality among Vietnam veterans. JAMA 1987;257:790-5

28. The Centers for Disease Control Vietnam Experience Study. Health status of Vietnam veterans. I. Psychosocial characteristics. JAMA 1988;259:2701-7.

29. The Centers for Disease Control Vietnam Experience Study. Health status of Vietnam veterans. II. Physical Health. JAMA 1988;259:2708-14.

30. The Centers for Disease Control Vietnam Experience Study. Health status of Vietnam veterans. III. Reproductive outcomes and child health. JAMA 1988:259:2715-19.
31. Boehmer TK, Flanders WD, McGeehin MA, et al. Postservice mortality in Vietnam veterans: 30-year follow-up. Arch Intern Med 2004;164:1908-16.

32. Duncan 0. A socioeconomic index for all occupations. New York: Free Press, 1961

33. Stevens G,.Cho J. Socioeconomic indexes and the new 1980 census occupational classification scheme. Soc Sci Res 1985;14:142-68.

34. Blair SN, Kannel WB, Kohl HW, et al. Surrogate measures of physical activity and physical fitness. Am J Epidemiol 1989;129:1145-56.

35. Davey Smith G, Shipley MJ, Batty GD, et al. Physical activity and cause-specific mortality in the Whitehall study. Public Health 2000;114:308-15.

36. Gunnell D. Can adult anthropometry be used as a "biomarker" for prenatal and childhood exposures? Int J Epidemiol 2002;31:390-4.

37. Batty GD, Gunnell D, Langenberg $C$, et al. Adult height and lung function as markers of life course exposures: associations with risk factors and cause-specific mortality. Eur J Epidemiol 2006;21:795-801.

38. Gale C. Commentary: Height and intelligence. Int J Epidemiol 2005:34:678-9.

39. Robins L, Helzer J, Cottler L, et al. Diagnostic Interview Schedule (version III-A) training manual. St Louis: Veterans Administration, 1987.

40. Robins LN. Epidemiology: reflections on testing the validity of psychiatric interviews. Arch Gen Psychiatry 1985;42:918-24.

41. American Psychiatric Association. Diagnostic and statistical manual of mental disorders, 3rd ed. Washington DC: American Psychiatric Association, 1980

42. Cox DR. Regression models and life-tables. J R Stat Soc [Ser B] 1972;34:187-220

43. Batty GD, Der G, Maclntyre $S$, et al. Does IO explain socioeconomic inequalities in health? Evidence from a population based cohort study in the west of Scotland. BMJ 2006;332:580-4.

44. Davey Smith G, Lynch J. Life course approaches to socioeconomic differentials in health. In: Diana Kuh YB-S, ed. A life course approach to chronic disease epidemiology. Oxford: Oxford University Press, 2004:77-115.

45. Batty GD, Deary IJ. Education and mortality: a role for intelligence? J Epidemiol Community Health 2005;59:809-10.

46. Batty GD, Deary IJ. Education and mortality: the role of intelligence. Lancet 2005:365:1765-6.

47. Deary IJ, Strand S, Smith $P$, et al. Intelligence and educational achievement. Intelligence 2007:35:13-21.

48. Deary IJ, Whalley LJ, Lemmon $\mathrm{H}$, et al. The stability of individual differences in mental ability from childhood to old age: follow-up of the 1932 Scottish mental survey. Intelligence 2000;28:49-55.

49. Whalley LJ, Deary IJ. Longitudinal cohort study of childhood IO and survival up to age 76. BMJ 2001;322:1-5.

50. Osler M, Andersen AM, Due P, et al. Socioeconomic position in early life, birth weight, childhood cognitive function, and adult mortality. A longitudinal study of Danish men born in 1953. J Epidemiol Community Health 2003;57:681-6.

51. Galobardes B, Lynch JW, Davey Smith G. Childhood socioeconomic circumstances and cause-specific mortality in adulthood: systematic review and interpretation. Epidemiol Rev 2004;26:7-21. 